\title{
Optimization and limitations of known DEMO divertor concepts
}

\author{
Jens Reiser, Michael Rieth \\ KIT, Institute for Applied Materials , 76344 Eggenstein-Leopoldshafen, Germany \\ E-mail: jens.reiser@kit.edu, Tel. +49 (0)721 60823894
}

\section{Introduction}

In this work we will introduce and discuss improvements of two types of DEMO divertors based on known designs: (i) a water cooled design and a (ii) gas cooled concept. For water cooled concepts the use of Eurofer is critical due to its severe embrittlement under neutron irradiation. Here we propose a live cycle operation which makes is possible to use Eurofer anyway. For a gas cooled concept, we make a proposal for a large scale divertor using the approved jet impingement and finally show a solution how to deal with the high gas temperature at the outlet: 'cooling of the coolant'.

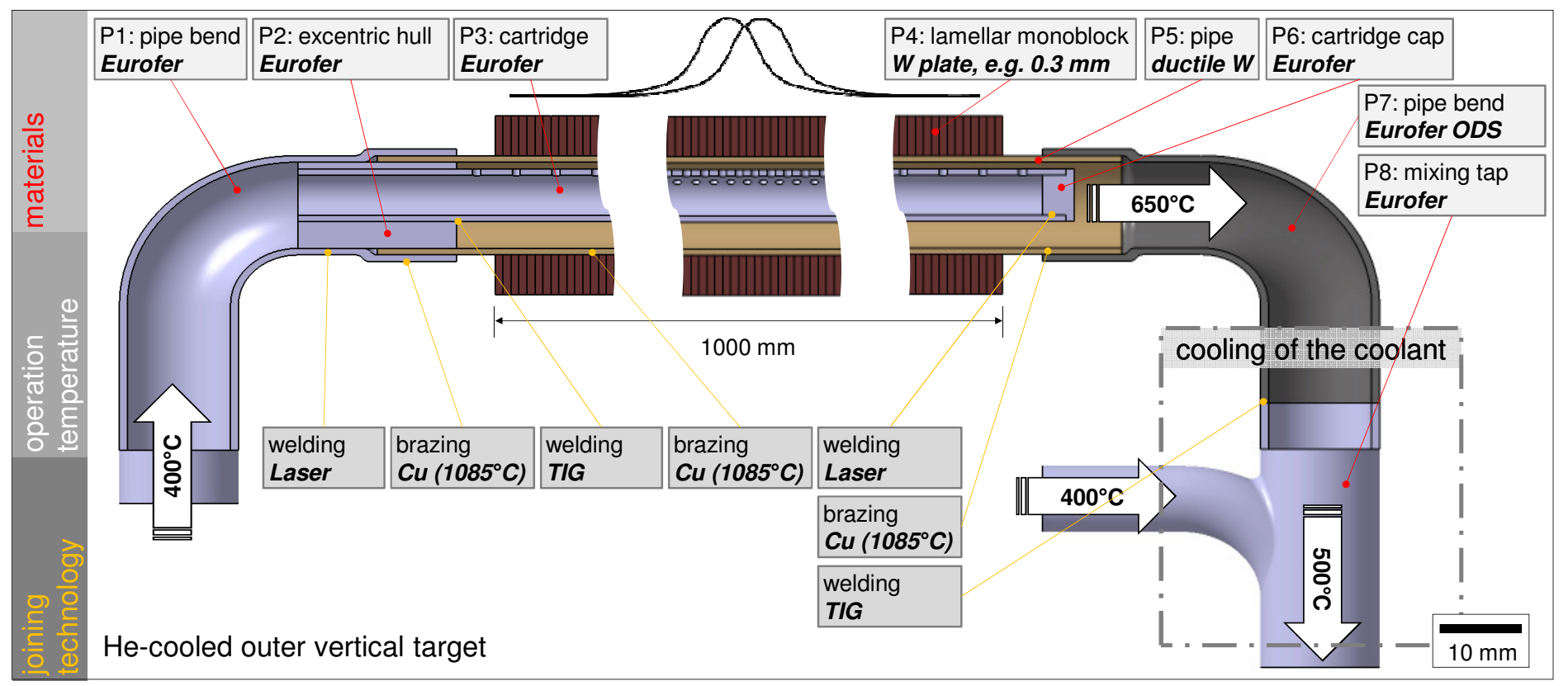

\section{Material limits}

The reduced activation ferritic-martensitic (RAFM) steels discussed here are Eurofer (Fe-9Cr-1.1W-0.2V-0.12Ta) and oxide dispersion strengthened Eurofer, Eurofer ODS. The material operation window is limited by the brittle- to-ductile transition temperature (dbtt) and the creep strength. The operation window of tungsten is limited on the lower end by the $\mathrm{dbtt}$ and on the upper limit by the creep strength or recrystallisation temperature. In this work, oxygen free high conductivity copper (OFHC $\mathrm{Cu}$ ) is uses as brazing material. For pure cupper the maximum swelling peak occurs between $300^{\circ} \mathrm{C}-350^{\circ} \mathrm{C}$.

\section{Eurofer: $\quad 350^{\circ} \mathrm{C}-550^{\circ} \mathrm{C}$ \\ Eurofer ODS: $350^{\circ} \mathrm{C}-650^{\circ} \mathrm{C}$ \\ tungsten: $\quad 300^{\circ} \mathrm{C}-800^{\circ} \mathrm{C}$ (new tungsten material) \\ OFHC Cu: $\quad>350^{\circ} \mathrm{C}$}

\section{Assembling, joining, heat treatment}

The assembling and joining order is as follows:

1) $P 3+P 6$ : laser welding

2) $P 3+P 2:$ TIG welding

3) $P 1+P 2$ : laser welding

4) $\mathrm{P} 1+\mathrm{P} 4+\mathrm{P} 5+\mathrm{P} 7$ : brazing with copper in one step $\left(\mathrm{T}_{\text {, brazing }}=1150^{\circ} \mathrm{C}\right)$

Brazing and austenitization is combined in one step.

5) quenching / hardening

6) tempering, $750^{\circ} \mathrm{C} / 2 \mathrm{~h}$

7) P7 + P8: TIG welding

\section{Live cycle operation}

Neutron irradiation at or below $350^{\circ} \mathrm{C}$ strongly degrades the impact properties of Eurofer, but this can be almost completely recovered by a post-irradiation heat treatment at $550^{\circ} \mathrm{C}$ [E. Gaganidze et al., J. Nucl. Mater. (2011)]. Therefore we propose the following live cycle operation:

- six month operation

- a few hours annealing at $550^{\circ} \mathrm{C}$ with helium

- four month operation

- a few hours annealing at $550^{\circ} \mathrm{C}$ with helium

- one month operation $\rightarrow$ replacement

\section{Cooling of the coolant}

The gas at the outlet is hot but could be managed by Eurofer ODS, which is expensive. To reduce costs it is aimed to use Eurofer as much as possible. As an improvement of existing divertor concepts we propose the "cooling of the coolant' using a mixing tap.

\section{Open issues}

1) Is the cooling performance (the heat transfer coefficients) at the end of the cartridge as good as on the beginning?

2) The tungsten pipe is ductile at $300^{\circ} \mathrm{C}$ measured by Charpy tests. But is it also ductile after neutron irradiation?

\section{Acknowledgement}

The authors are grateful to all the colleagues from the Institute for Applied Materials for their support and fruitful discussions. 